\title{
Evaluation of plasma antimicrobial peptide LL-37 and nuclear factor-kappaB levels in stable chronic obstructive pulmonary disease
}

This article was published in the following Dove Medical Press journal: International Journal of COPD

\author{
Pelin Uysal' \\ Gonul Simsek ${ }^{2}$ \\ Sinem Durmus ${ }^{3}$ \\ Volkan Sozer ${ }^{4}$ \\ Hulya Aksan ${ }^{5}$ \\ Sibel Yurt ${ }^{6}$ \\ Caglar Cuhadaroglu' \\ Filiz Kosar ${ }^{6}$ \\ Remise Gelisgen ${ }^{3}$ \\ Hafize Uzun ${ }^{3}$ \\ 'Department of Chest Diseases, \\ Faculty of Medicine, Mehmet Ali \\ Aydınlar University, Atakent Hospital, \\ Istanbul, Turkey; ${ }^{2}$ Department of \\ Physiology, Cerrahpasa Faculty \\ of Medicine, Istanbul University- \\ Cerrahpasa, Istanbul, Turkey; \\ ${ }^{3}$ Department of Biochemistry, \\ Cerrahpasa Faculty of Medicine, \\ Istanbul University-Cerrahpasa, \\ Istanbul, Turkey; ${ }^{4}$ Department \\ of Biochemistry, Yildiz Technical \\ University, Istanbul, Turkey; \\ ${ }^{5}$ Deparment of Biochemistry, Faculty \\ of Medicine, Halic University, İstanbul, \\ Turkey; ${ }^{6} \mathrm{Clinic}$ of Chest Diseases, \\ Yedikule Chest Diseases and Chest \\ Surgery Training and Research \\ Hospital, İstanbul, Turkey
}

Correspondence: Hafize Uzun Department of Medical Biochemistry, Cerrahpasa Faculty of Medicine, Istanbul University-Cerrahpasa, 34303 Cerrahpasa, Istanbul, Turkey

Tel +90212 4143056

Fax +902126332987

Email huzun59@hotmail.com
Background: Antimicrobial peptides are effectors of host defence against infection and inflammation and can encourage wound repair.

Objectives: The objectives of this study were to investigate the plasma antimicrobial peptide LL-37 and nuclear factor-kappaB (NF-אB) levels in patients with stable COPD compared with a control group and to highlight their importance in immune inflammation.

Methods: One hundred and thirty-eight stable COPD patients and 33 control subjects were enrolled in the study. The COPD patients were classified into four groups based on FEV (groups I-IV) and also divided into "low-risk and high-risk" groups (groups A-B [low risk], C-D [high risk]).

Results: Plasma LL-37 levels were significantly lower while plasma NF- $\kappa$ B levels of the COPD patients were significantly higher than those of the control subjects $(P<0.001$, both). LL-37 levels

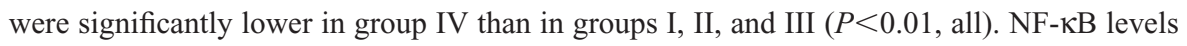
were significantly higher in groups III and IV than in groups I and II $(P<0.05$, both). There was a positive correlation between $\mathrm{FEV}_{1}$ and $\mathrm{FEV}_{1} / \mathrm{FVC}$ in all COPD patients $(r=0.742, P<0.001)$ and in group $\mathrm{D}(r=0.741, P<0.001)$. Furthermore, there was an inverse correlation between LL-37 and NF- $\kappa \mathrm{B}$ in both the groups $\mathrm{C}(r=-0.566, P<0.001)$ and $\mathrm{D}(r=-0.694, P<0.001)$ and group $\mathrm{C}+\mathrm{D}$ combined $(r=-0.593, P<0.001)$. Furthermore, in group $\mathrm{C}, \mathrm{LL}-37$ and $\mathrm{FEV} \mathrm{F}_{1}$ were positively correlated $(r=0.633, P<0.001)$.

Conclusion: Our study indicated that plasma LL-37 and NF- $\kappa$ B may play an important role in chronic immune inflammation. Decreased LL-37 levels may be particularly high risk for patients in stage IV disease. The role of LL-37 as a target for treatment of the immune system and COPD must be widely evaluated.

Keywords: COPD, inflammation, antimicrobial peptide LL-37, nuclear factor kappaB

\section{Introduction}

COPD is common worldwide and has a major impact on the health care burden. ${ }^{1}$ The Global Initiative for Chronic Obstructive Lung Disease (GOLD) defines COPD as a disease that is "usually progressive and associated with an enhanced chronic inflammatory response in the airways and the lung to noxious particles or gases. ${ }^{\prime 2} \mathrm{COPD}$ is characterized by a progressive inflammation of the airways, the alveoli, and the microvasculature; which among these aspects are preventable and treatable is still debatable. ${ }^{1}$

Cathelicidin is a kind of protein present in the innate immunity of mammals and serves as precursor molecule that can release an antimicrobial peptide after proteolytic cleavage. ${ }^{3}$ Cathelicidin (LL-37 or hCAP-18) is a small cationic peptide produced by neutrophils, monocytes, macrophages, mast cells, natural killer (NK) cells, 
B and T cells, epithelial cells, and keratinocytes. Cathelicidin kills a wide range of infectious agents including grampositive and gram-negative bacteria and some viruses and fungi by disrupting their membranes, and it neutralizes the activity of bacterial endotoxins, thus playing a vital role in antimicrobial defense. ${ }^{4,5}$ Studies investigating the role of this protein in COPD indicate that LL-37 may contribute to the progression of the disease by increasing airway mucus production in COPD. ${ }^{6-8}$

Nuclear factor-kappaB $(\mathrm{NF}-\kappa \mathrm{B})$ is a crucial transcription factor in a wide range of inflammatory networks that regulate cytokine activity in airway pathology. ${ }^{9}$ It has been reported that activated NF- $\kappa$ B levels are increased in bronchial biopsies and inflammatory cells of individuals with COPD. ${ }^{10,11}$

LL-37 induced the activation of the NF- $\kappa B$ signaling pathway by the evaluation of I $\mathrm{K}-\mathrm{B} \alpha$ phosphorylation/ degradation and NF- $\kappa \mathrm{B}$ p50/p65 nuclear subunit translocation. Then, this activated signaling pathway led to the LL-37-stimulated production of IL-6. The LL-37-mediated activation of the NF- $\kappa \mathrm{B}$ signaling pathway in airway epithelial cells is a novel effect of this host defense peptide. ${ }^{12}$ The effect of LL-37 on NF- $\kappa B$ is conflicting in COPD. NF- $\kappa B$ seems to have a key role in airway inflammation in COPD.

To the best of our knowledge, there is no study yet of the association of plasma LL-37 and NF- $\mathrm{KB}$ levels in stable COPD. Therefore, the primary aim of this study was to evaluate the plasma antimicrobial peptide LL-37 and NF- $\mathrm{KB}$ levels in stable COPD patients and compare it with a control group to highlight their importance in chronic immune inflammation.

\section{Materials and methods}

The present study was conducted with the approval of the ethics committee of Cerrahpasa Medical Faculty, Istanbul University, and written informed consent was provided by all the participating subjects. This study was conducted in accordance with the tenets of the Declaration of Helsinki. This is a prospective study conducted in the Acibadem University School of Medicine, Acibadem Atakent Hospital, Department of Chest Disease and Yedikule Chest Disease and Chest Surgery Education and Research Hospital between May 2016 and December 2016. One hundred and thirtyeight stable COPD patients and 33 controls were enrolled in this study. The COPD patients were diagnosed based on the 2016 GOLD, and they were classified into four groups based on FEV 1 (groups I [mild], II [moderate], III [severe], and IV [very severe]). Another classification of patients were made according to the GOLD guidelines which uses a combined COPD assessment approach to group patients according to symptoms and previous history of exacerbations. These can be found in the GOLD guideline. ${ }^{13}$ In this classification, patients were divided into "low-risk and highrisk" groups (groups A-B [low risk], C-D [high risk]) based on the COPD risk according to the evaluation standards defined by the GOLD committee.

\section{Exclusion criteria}

1. Respiratory disorders other than COPD, pulmonary embolism, and left ventricular systolic or diastolic dysfunction

2. Comorbidities such as diabetes, chronic renal insufficiency, hyperthyroidism, hypothyroidism, hepatic dysfunction, and lower respiratory tract infection

3. COPD attack in the last 6 weeks

4. Presence of metabolic syndrome.

Thirty-three control subjects were selected from a group of healthy subjects who presented at the Department of Chest Diseases for regular health control or check-up. Detailed history was taken from all the participants, and physical examinations were performed. Spirometry tests were performed in accordance with the criteria recommended by the European Respiratory Society (ERS) using a computerassisted spirometry (Vmax22D; Sensor Medics, CA, USA). Pulmonary function parameters such as $\mathrm{FEV}_{1}, \mathrm{FVC}$, and $\mathrm{FEV}_{1} / \mathrm{FVC}$ ratio were measured, and the absolute values and the percentage of expected values of these parameters were analyzed.

\section{Laboratory analysis}

\section{Sample collection and preparation}

Venous blood samples were collected in the morning in tubes containing ethylenediaminetetraacetic acid and anticoagulant-free tubes after 12 hours fasting and before drug use. Plasma and serum samples were separated by centrifugation at $3,000 \times g$ for 10 minutes at $4{ }^{\circ} \mathrm{C}$, and then separated in microcentrifuge tubes and frozen immediately at $-80^{\circ} \mathrm{C}$ until analysis.

Routine biochemical parameters were measured by the autoanalyzer (Hitachi Modular System; Hoffman-La Roche Ltd., Basel, Switzerland). Serum C-reactive protein (CRP) levels were measured by a nephelometric method (Immage 800 Beckman Coulter, Brea, CA, USA). Complete blood count parameters were obtained with automatic hematology analyzer (Siemens-Sysmex, Germany). Erythrocyte sedimentation rate (ESR) was measured according to the Westergren method with an established normal range $(0-20 \mathrm{~mm} / \mathrm{h})$. 


\section{Measurement of plasma antimicrobial peptide LL-37 levels}

Plasma LL-37 levels were measured by a solid-phase ELISA kit based on the sandwich principle (Cat. No HK321; Hycult Biotech, the Netherlands). Calculated intra- and inter-assay coefficients of variation (CVs) were 4.7\% $(n=20)$ and $5.6 \%$ $(n=20)$ for this kit, respectively.

\section{Measurement of plasma NF- $\kappa B$ levels}

Plasma NF- $\kappa B$ levels were measured by quantitative sandwich ELISA kit (Cat. No MBS260718; eBioscience, Austria). Calculated intra- and inter-assay CVs were $4.8 \%(\mathrm{n}=20)$ and $5.9 \%(n=20)$ for this kit, respectively.

\section{Statistical analysis}

Statistical analyses were performed using the SPSS 20.0 (IBM Corporation, Armonk, NY, USA). All data were first checked for normality. Normally distributed continuous variables were presented as mean \pm SD and analyzed by one-way ANOVA followed by Tukey's multiple comparison tests. Pearson and Spearman's correlations were used for numerical and nominal data, respectively. Receiver operating characteristic (ROC) analysis and area under the ROC curve (AUC) were used to assess the diagnostic accuracy. Differences were considered significant when the $P$-value was $<0.05$.

\section{Results}

The demographic features of the patients and the control group are given in Table 1. As expected, severe and very severe groups have significantly lower $\mathrm{FEV}_{1}$ and $\mathrm{FEV}_{1} / \mathrm{FVC}$ levels than other groups (each $P<0.001$ ). The lowest plasma LL-37 levels were found in the very severe group. NF- $\kappa B$ levels in very severe group were significantly higher than other groups $(P<0.001)$.

Clinical and laboratory findings of the groups were classified according to the GOLD criteria as given in Table 2 . Bar graphs of LL-37 and NF- $\kappa B$ levels according to GOLD stages are depicted in Figures 1 and 2. $\mathrm{FEV}_{1}$ and $\mathrm{FEV}_{1} / \mathrm{FVC}$ in the $\mathrm{C}$ and $\mathrm{D}$ groups were significantly lower than controls and $\mathrm{A}$ and $\mathrm{B}$ groups (each $P<0.001$ ). $\mathrm{FEV}_{1}$ and $\mathrm{FEV}_{1} / \mathrm{FVC}$ in $\mathrm{A}$ and $\mathrm{B}$ groups were found to be lower than the control group $(P<0.001)$. ESR levels were only found to be different in $\mathrm{A}$ and $\mathrm{B}$ groups and $\mathrm{C}$ and $\mathrm{D}$ groups as compared to the controls $(P<0.05)$. CRP values were not significantly different among COPD stages, both in the A and $\mathrm{B}$ groups and control groups. $\mathrm{CRP}$ levels of the $\mathrm{C}$ and $\mathrm{D}$ groups were higher than the controls and $\mathrm{A}$ and $\mathrm{B}$ groups $(P<0.01)$. Plasma LL-37 levels in the A and B groups $(P<0.01)$ and the control group $(P<0.001)$ were significantly higher than that in the $\mathrm{C}$ and $\mathrm{D}$ groups. Plasma LL-37 levels in the $\mathrm{A}$ and $\mathrm{B}$ groups were not different from the control group. The $\mathrm{C}$ and $\mathrm{D}$ groups had higher NF- $\mathrm{\kappa B}$ levels than both the control and $\mathrm{A}$ and $\mathrm{B}$ groups (both $P<0.001$ ). There was no significant difference in NF- $\mathrm{KB}$ levels between the control group and $\mathrm{A}$ and $\mathrm{B}$ groups.

ROC analysis for clinical and laboratory findings for all groups is shown in Figure 3. There was a positive correlation between $\mathrm{FEV}_{1}$ and $\mathrm{FEV}_{1} / \mathrm{FEVC}$ in all COPD patients $(r=0.742, P<0.001)$ and in group D $(r=0.741, P<0.001)$. Moreover, there was a negative correlation between LL-37 and NF- $\mathrm{KB}$ in group $\mathrm{C}(r=0.566, P<0.001)$, group D ( $r=-0.694, P<0.001)$, and group $\mathrm{C}+\mathrm{D}$ combined $(r=-0.593$, $P<0.001)$. Furthermore, LL-37 and $\mathrm{FEV}_{1}$ were positively correlated $(r=0.633, P<0.001)$ in group $\mathrm{C}$.

Table I Demographic, clinical, and laboratory findings of the groups

\begin{tabular}{|c|c|c|c|c|c|}
\hline & $\begin{array}{l}\text { Control } \\
(n=33)\end{array}$ & $\begin{array}{l}\text { Mild (group I) } \\
(n=34)\end{array}$ & $\begin{array}{l}\text { Moderate (group II) } \\
(n=35)\end{array}$ & $\begin{array}{l}\text { Severe (group III) } \\
(n=35)\end{array}$ & $\begin{array}{l}\text { Very severe } \\
\text { (group IV) }(n=34)\end{array}$ \\
\hline Age (year) & $58.45 \pm 6.61$ & $58.35 \pm 13.39^{\mathrm{d} 3, \mathrm{e} 3}$ & $60.40 \pm 9.31^{\mathrm{d} 3, \mathrm{e} 3}$ & $66.46 \pm 1 \mid .88^{\mathrm{a} 3, \mathrm{b3}}$ & $69.32 \pm 11.63^{\mathrm{a} 3, \mathrm{~b} 3, \mathrm{c} 3}$ \\
\hline Female/male & $16 / 17$ & $\mathrm{II} / 23$ & $|4 / 2|$ & $7 / 28$ & $9 / 25$ \\
\hline $\mathrm{FEV}_{1}(\%)$ & $101.79 \pm 8.54$ & $91.29 \pm 1 \mid .26^{\mathrm{a} 3, \mathrm{c} 3, \mathrm{~d} 3, \mathrm{e} 3}$ & $67.80 \pm 2.86^{\mathrm{a} 3, \mathrm{~b} 3, \mathrm{~d} 3, \mathrm{e} 3}$ & $46.97 \pm 3.29^{\mathrm{a} 3, \mathrm{~b} 3, \mathrm{c}, \mathrm{e} 3}$ & $27.38 \pm 2.04^{\mathrm{a} 3, \mathrm{~b} 3, \mathrm{c} 3, \mathrm{~d} 3}$ \\
\hline $\mathrm{FEV}_{1} / \mathrm{FVC}$ & $83.70 \pm 4.50$ & $67.53 \pm 4.64^{\mathrm{a} 2, \mathrm{c} 3, \mathrm{~d} 3, \mathrm{e} 3}$ & $65.37 \pm 6.54^{\mathrm{a} 3 \mathrm{~d} \mathrm{~d} 3 \mathrm{e} 3}$ & $59.86 \pm 8.65^{\mathrm{a} 3, \mathrm{~b} 3, \mathrm{c}, \mathrm{e} 3}$ & $43.91 \pm 3.38^{\mathrm{a} 3, \mathrm{~b} 3, \mathrm{c} 3, \mathrm{~d} 3}$ \\
\hline WBC $\left(\times 10^{3} / \mu \mathrm{L}\right)$ & $7.16 \pm 1.51$ & $8.92 \pm 2.99^{a l}$ & $7.59 \pm 2.07$ & $8.13 \pm 2.67$ & $10.03 \pm 3.46^{\mathrm{a} 2}$ \\
\hline Total protein $(\mathrm{g} / \mathrm{dL})$ & $8.07 \pm 0.35$ & $7.50 \pm 0.39^{a 3}$ & $7.31 \pm 0.60^{\mathrm{a} 3}$ & $7.28 \pm 0.45^{\mathrm{a} 3}$ & $6.92 \pm 0.69^{\mathrm{a} 3}$ \\
\hline Albumin (g/dL) & $4.06 \pm 0.27$ & $3.72 \pm 0.29$ & $3.66 \pm 0.43$ & $3.44 \pm 0.44$ & $3.40 \pm 0.51$ \\
\hline $\mathrm{ESR}(\mathrm{mm} / \mathrm{h})$ & $10.61 \pm 8.56$ & $19.68 \pm 16.75^{\mathrm{a} 3}$ & $18.73 \pm 11.13^{\mathrm{a} 3}$ & $22.17 \pm 14.26^{\mathrm{a} 3}$ & $22.03 \pm 14.77^{\mathrm{a} 3}$ \\
\hline CRP (mg/L) & $0.32 \pm 0.18$ & $0.60 \pm 0.60^{\mathrm{al}, \mathrm{dl}}$ & $0.52 \pm 0.50$ & $0.74 \pm 0.67^{\mathrm{a} 2, \mathrm{bl}, \mathrm{el}}$ & $0.56 \pm 0.39^{\mathrm{al}, \mathrm{dl}}$ \\
\hline LL-37 (pg/mL) & $368 \pm 126$ & $310 \pm 86^{\mathrm{c} 2, \mathrm{~d} 2, \mathrm{el}}$ & $288 \pm 100^{\mathrm{a} 2, \mathrm{~b} 2, \mathrm{el}}$ & $288 \pm\left. 8\right|^{\mathrm{a} 3, \mathrm{~b} 3, \mathrm{el}}$ & $25 I \pm \mid 36^{\mathrm{a} 3, \mathrm{~b} 3, \mathrm{cl}, \mathrm{dl}}$ \\
\hline NF- $\kappa B(n g / m L)$ & $2.93 \pm 0.81$ & $3.32 \pm \mathrm{I} .03^{\mathrm{cl}, \mathrm{dl}, \mathrm{e} 3}$ & $3.97 \pm 1.83^{\mathrm{al}, \mathrm{e} 3}$ & $3.95 \pm\left. 1.7\right|^{\mathrm{al}, \mathrm{e} 3}$ & $4.85 \pm 1.77^{\mathrm{al}, \mathrm{bl}}$ \\
\hline
\end{tabular}

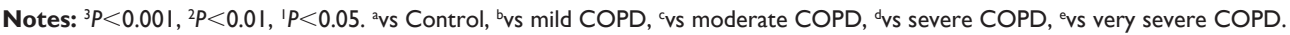

Abbreviations: WBC, white blood cell; ESR, erythrocyte sedimentation rate; CRP, C-reactive protein; NF- $\mathrm{B}$, nuclear factor-kappaB. 
Table 2 Clinical and laboratory findings of the groups according to GOLD stage

\begin{tabular}{l|l|l|l}
\hline & Control $(\mathbf{n}=\mathbf{3 3})$ & A and B groups $(\mathbf{n}=\mathbf{6 9})$ & C and $\mathbf{D}$ groups $(\mathbf{n}=\mathbf{6 9})$ \\
\hline $\mathrm{FEV}_{1}(\%)$ & $101.79 \pm 8.67$ & $79.38 \pm\left. 14.4\right|^{\mathrm{a}, \mathrm{c} 3}$ & $37.32 \pm 10.25^{\mathrm{a} 3, \mathrm{~b} 3}$ \\
$\mathrm{FEV}_{1} / \mathrm{FVC}(\%)$ & $83.70 \pm 4.57$ & $66.43 \pm 5.83^{\mathrm{a}, \mathrm{cc}}$ & $52.00 \pm 10.42^{\mathrm{a} 3, \mathrm{~b} 3}$ \\
$\mathrm{WBC}\left(\times 10^{3} / \mu \mathrm{L}\right)$ & $7.16 \pm 1.5 \mathrm{I}$ & $8.24 \pm 2.65^{\mathrm{a} 1}$ & $9.07 \pm 3.23^{\mathrm{a} 3}$ \\
Total protein $(\mathrm{g} / \mathrm{dL})$ & $8.07 \pm 0.35$ & $7.40 \pm 0.52^{\mathrm{a}, \mathrm{c} 2}$ & $7.10 \pm\left. 0.6\right|^{\mathrm{a} 3, \mathrm{~b} 2}$ \\
Albumin $(\mathrm{g} / \mathrm{dL})$ & $4.06 \pm 0.27$ & $3.69 \pm 0.37$ & $3.42 \pm 0.48$ \\
ESR $(\mathrm{mm} / \mathrm{h})$ & $10.61 \pm 8.56$ & $19.19 \pm 14.29^{\mathrm{a} 2}$ & $22.10 \pm 14.62^{\mathrm{a} 3}$ \\
CRP $(\mathrm{mg} / \mathrm{L})$ & $0.32 \pm 0.18$ & $0.55 \pm 0.56^{\mathrm{a} 1}$ & $0.65 \pm 0.56^{\mathrm{a} 2}$ \\
\hline
\end{tabular}

Notes: ${ }^{3} P<0.001,{ }^{2} P<0.01,{ }^{\prime} P<0.05$. a vs control, ${ }^{b} v s \mathrm{~A}$ and $B$ groups, ${ }^{\mathrm{C}} \mathrm{vs} C$ and $\mathrm{D}$ groups.

Abbreviations: WBC, white blood cell; ESR, erythrocyte sedimentation rate; CRP, C-reactive protein; GOLD, The Global Initiative for Chronic Obstructive Lung Disease.

The effectiveness of the investigated biochemical parameters and clinical findings in the early recognition of patients with COPD was assessed using ROC analysis. Figure 4 shows the ROC curves for all biochemical parameters and clinical findings that we investigated for all patients. In addition, Tables 3-6 show the AUC, cutoff, sensitivity, and specificity values for all investigated parameters for controls vs $\mathrm{C}+\mathrm{D}$ groups, $\mathrm{A}+\mathrm{B}$ vs $\mathrm{C}+\mathrm{D}$ groups, controls vs $\mathrm{A}+\mathrm{B}$ groups, and controls and all patients, respectively. ROC analysis revealed that $\mathrm{FEV}_{1}$ and $\mathrm{FEV}_{1} / \mathrm{FVC}$ had the best diagnostic value in differentiating both disease severity and disease state prediction. Moreover, LL-37 has also been shown to be a good parameter for this purpose.

\section{Discussion}

Research-based evidence has indicated that infection and innate immunity play pivotal roles in COPD. Antimicrobial peptides are effector molecules of the innate immune system of the lung. ${ }^{14}$ In the current study, plasma LL-37 levels in the $\mathrm{A}$ and $\mathrm{B}$ groups and control group were significantly higher than that in the $\mathrm{C}$ and $\mathrm{D}$ groups. The $\mathrm{C}$ and $\mathrm{D}$ groups had

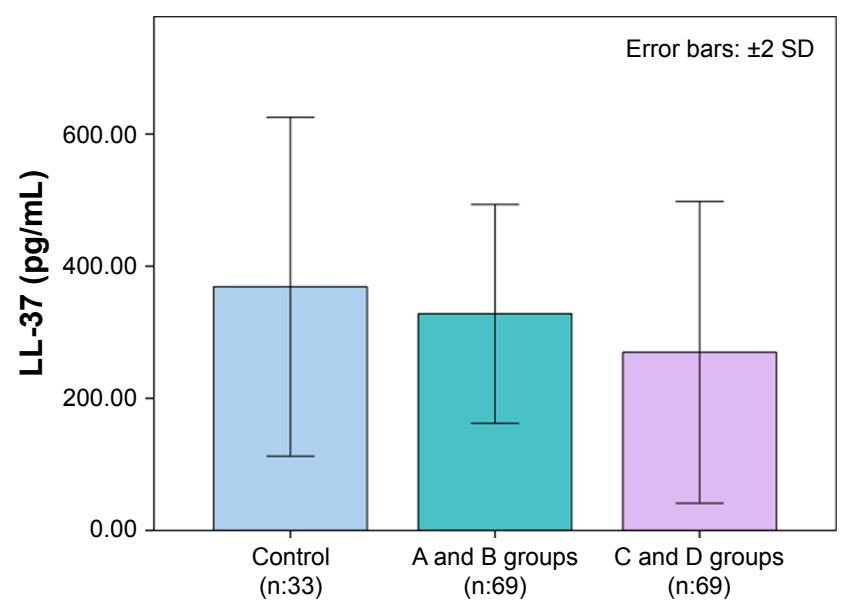

Figure I LL-37 levels according to GOLD stages.

Abbreviation: GOLD, The Global Initiative for Chronic Obstructive Lung Disease. higher NF- $\mathrm{KB}$ levels than both the control group and A and $\mathrm{B}$ groups. There was also a positive correlation between LL-37 and $\mathrm{FEV}_{1}$, and LL-37 and $\mathrm{FEV}_{1} / \mathrm{FVC}$, while there was a negative correlation with NF- $\mathrm{KB}$ in all COPD patients. The role of LL-37 as a human cathelicidin antimicrobial peptide in the pathogenesis of COPD has been previously reported. ${ }^{6-8}$ LL-37 might be regulated by inflammatory stimuli in COPD. Pistolic et $\mathrm{al}^{12}$ reported that LL-37 activates the NF- $\kappa B$ signaling in human airway epithelial cells, leading to both pro-inflammatory and anti-inflammatory effects by activating different molecules such as IL-6 and IL-8. Thus, we speculated that LL-37 might be inhibited by the activating properties of NF- $\mathrm{KB}$ in COPD.

The role of LL-37 in COPD has been evaluated by many studies, with conflicting results. Low LL-37 was found to be associated with poor prognosis in several conditions such as chronic dialysis, ${ }^{15}$ sepsis, ${ }^{16}$ neutropenia of various etiologies, ${ }^{17}$ psoriasis, ${ }^{18}$ and tuberculosis (TB) ${ }^{19}$ as well as COPD. In these patients, the results are controversial as in COPD. Jiang et $\mathrm{al}^{20}$ found that COPD III + IV patients had increased LL-37 levels

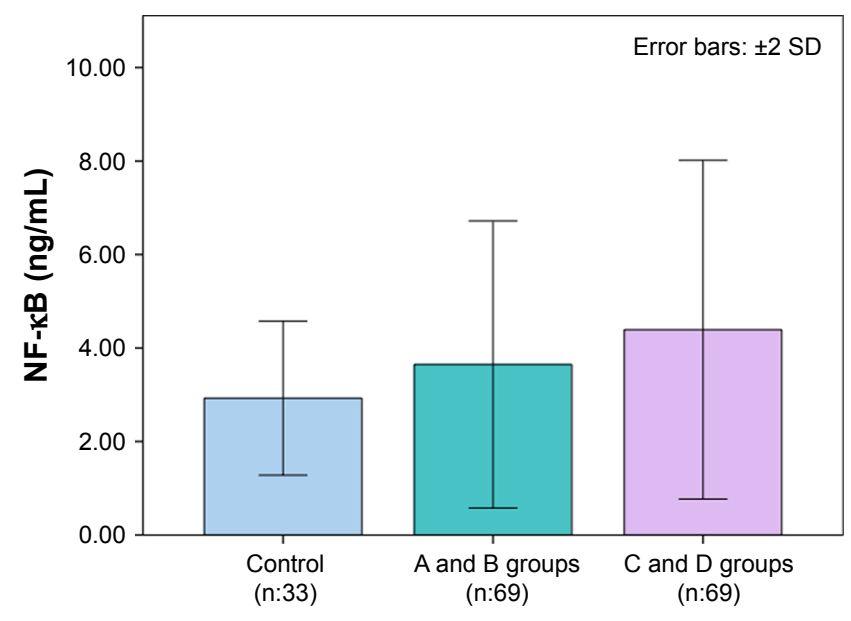

Figure $2 \mathrm{NF}-\mathrm{\kappa B}$ levels according to GOLD stages.

Abbreviations: NF- $\kappa B$, nuclear factor-kappaB; GOLD, The Global Initiative for Chronic Obstructive Lung Disease. 

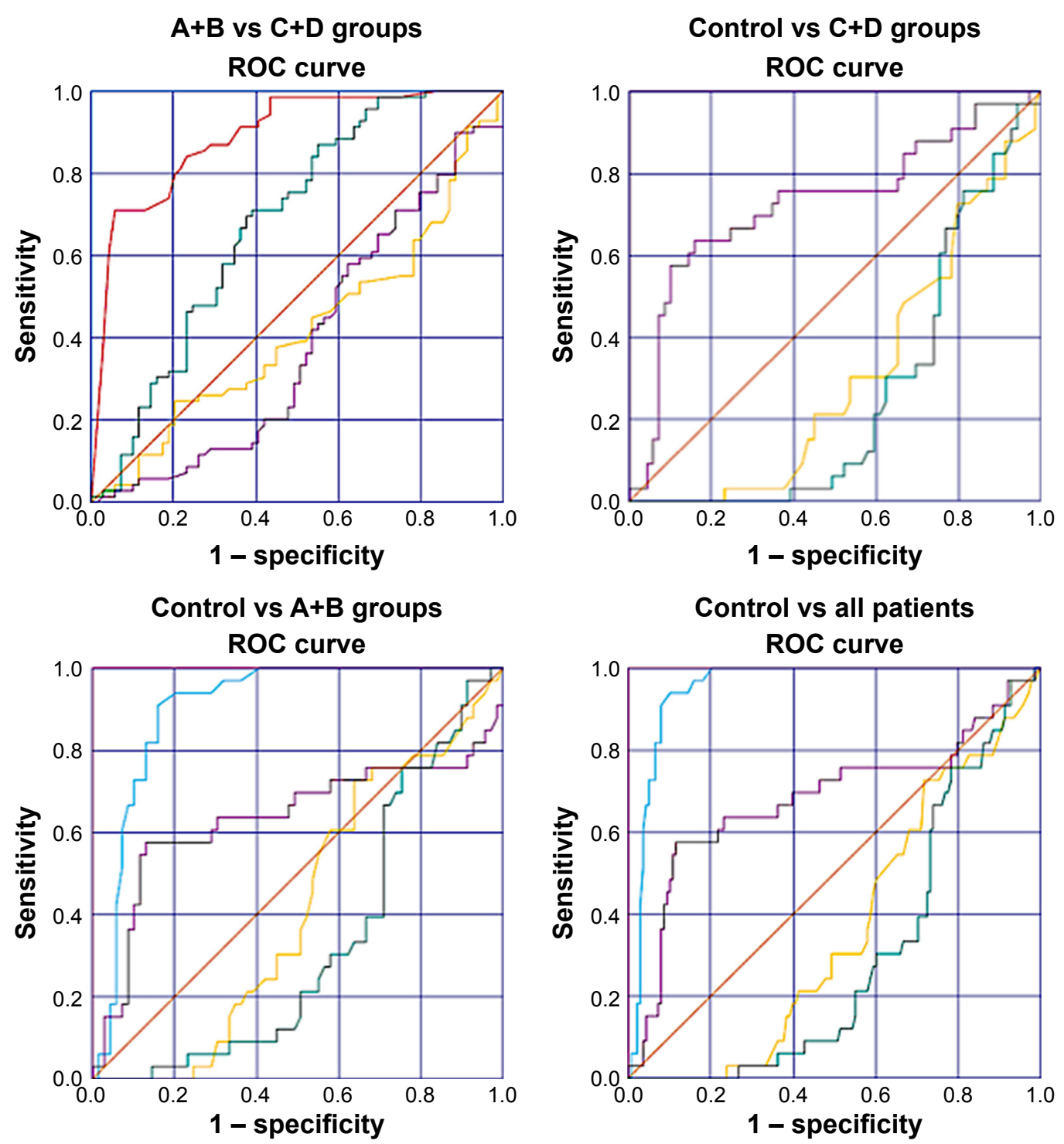

Source of the curve
$-\mathrm{FEV}_{1}-\mathrm{FEV}_{1} / \mathrm{FVC}-\mathrm{CRP}-\mathrm{LL}-37-\mathrm{NF}-\mathrm{KB}-$ Reference line

Figure $3 \mathrm{ROC}$ analysis for clinical and laboratory findings.

Abbreviations: ROC, Receiver operating characteristic; NF-kB, nuclear factor-kappaB.

as compared to COPD I + II patients. Our findings differ from these results. This contradictory result may be likely attributed to the limited number of patients in Jiang et al's study. ${ }^{20}$ Furthermore, the specimen type might be the reason for these differences, because significant incensement found in sputum, not serum samples, and they also stated that local production might be the cause of elevated LL-37 in sputum. The lowest plasma LL-37 levels were obtained from the very severe group in our study. There was also a positive correlation between FEV 1 and LL-37. LL-37 levels in sputum and bronchoalveolar lavage fluid (BALF) are upregulated in COPD patients. ${ }^{21,22}$ Similar to our results, Yang et $\mathrm{al}^{7}$ found that the plasma LL-37 levels were lower in COPD patients with high risk of frequent exacerbations than normal subjects. Low plasma levels of LL-37 might be predictors of exacerbation risk in COPD patients. Moreover, there was a negative association between LL-37 levels and the frequency of hospitalization for COPD exacerbations in these high-risk patients. Sun et $\mathrm{al}^{23}$ reported that LL-37 levels in BALF samples were significantly higher in patients with early stage COPD (GOLD I-II) than healthy individuals. The same was true for epithelial lining fluid (ELF). They found that patients with advanced COPD (GOLD III-IV) had significantly diminished LL-37 levels in both the BALF and ELF samples. 
A

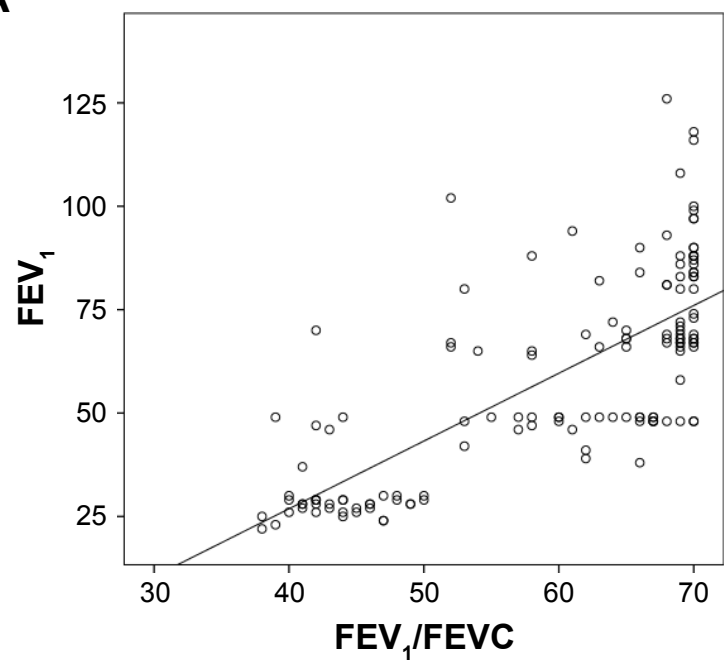

C

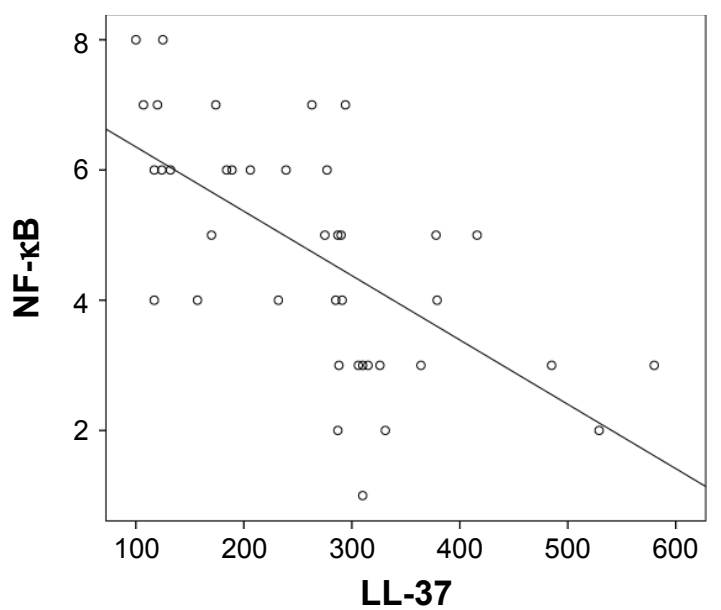

E

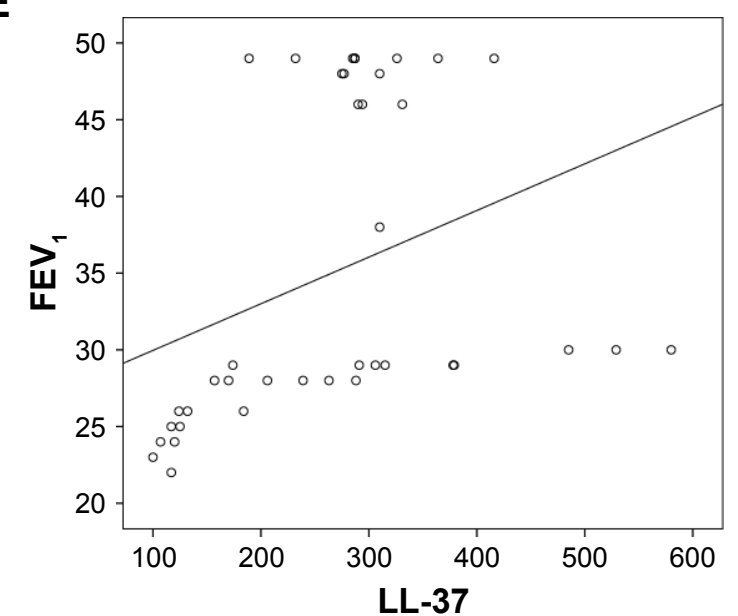

B

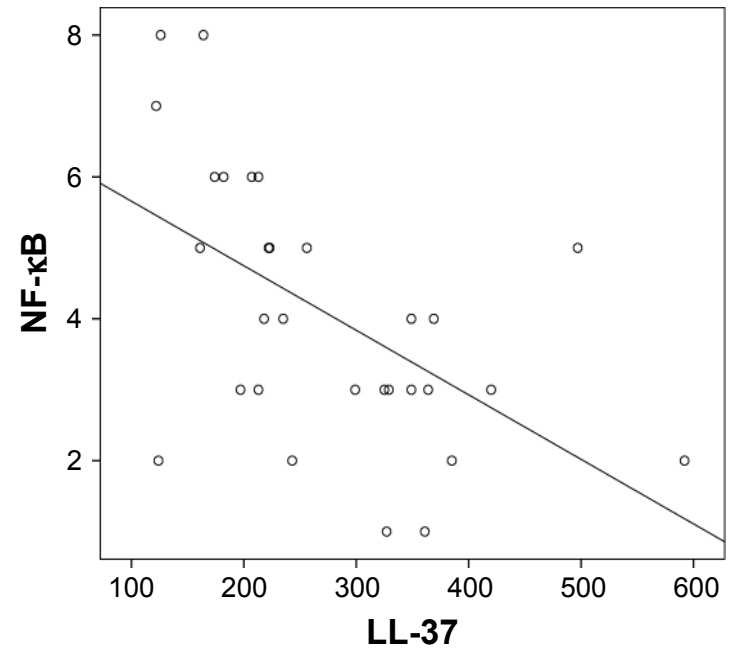

D

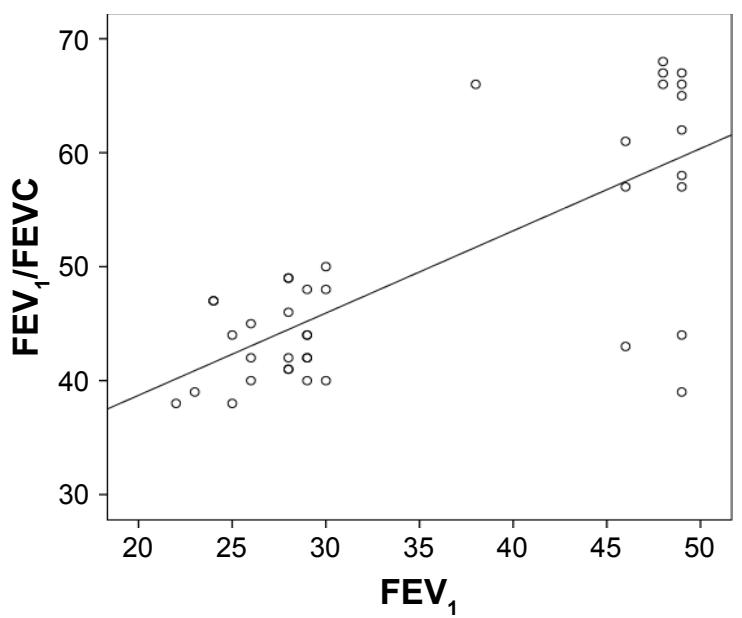

F

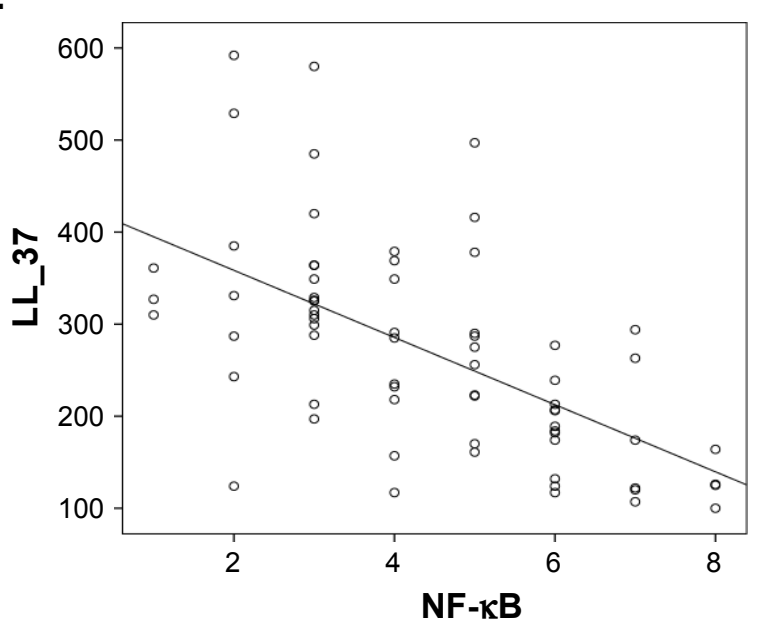

Figure 4 Correlation graphics of groups: (A) Correlation between FEV,/FEVC and FEV, in all COPD patients; (B) correlation between LL-37 and NF- KB in group C; (C) correlation between LL-37 and NF-KB in group D; (D) correlation between FEV, and FEV, /FEVC in group D; (E) correlation between LL-37 and FEV, in group D; and (F) correlation between NF-KB and LL-37 in group C+D.

Abbreviation: NF- $\kappa B$, nuclear factor-kappaB.

In addition, the significantly increased LL-37 levels both in BALF and ELF in patients with COPD at GOLD stages I-II together with reduced levels in advanced COPD (GOLD stages III-IV) further support the involvement of innate immunity in COPD pathology and suggest a profound change in non-specific immunity during disease progression. In our study, there was also a positive correlation between $\mathrm{FEV}_{1}$ and LL-37 in group IV. According to ROC analysis, 
Table 3 ROC analysis for clinical and laboratory findings of controls and C+D groups

\begin{tabular}{|l|l|l|l|l|l|l|l|}
\hline Control-CD & AUC & SE & P-value & 95\% CI & Cutoff & Sensitivity (\%) & Specificity (\%) \\
\hline FEV,$(\%)$ & 1.000 & 0.000 & $\leq 0.001$ & $1.000-1.000$ & 66.00 & 100 & 100 \\
\hline FEV $/$ /FVC (\%) & 1.000 & 0.000 & $\leq 0.001$ & $1.000-1.000$ & 73.00 & 100 & 100 \\
\hline CRP $(\mathrm{mg} / \mathrm{L})$ & 0.309 & 0.052 & $\leq 0.001$ & $0.207-0.410$ & 0.40 & 30.3 & 46.4 \\
\hline NF-KB $(\mathrm{ng} / \mathrm{mL})$ & 0.261 & 0.048 & $\leq 0.001$ & $0.168-0.355$ & 2.81 & 60.6 & 24.6 \\
\hline LL-37 $(\mathrm{pg} / \mathrm{mL})$ & 0.727 & 0.058 & $\leq 0.001$ & $0.613-0.841$ & 307 & 72.7 & 65.2 \\
\hline
\end{tabular}

Note: Bold type indicates specificity and/or sensitivity values are greater than $80 \%$.

Abbreviations: ROC, Receiver operating characteristic; CRP, C-reactive protein; NF- $\kappa B$, nuclear factor-kappaB; AUC, area under the curve.

LL-37 has the best sensitivity (84\%) to distinguish groups $\mathrm{C}$ and $\mathrm{D}$ from groups $\mathrm{A}$ and $\mathrm{B}$. Despite all the complexity, the assessment of exacerbation risk is important in accurate COPD grading. Respiratory tract infection is the most common cause of COPD exacerbation. LL-37 is the only known human cathelicidin antimicrobial peptide to play a crucial role in innate defense against infection. Detection of decreased LL-37 levels could help to differentiate patients with high risk of COPD exacerbations. Accordingly, LL-37 could act as a good indicator of exacerbations in COPD. Our results have shown that LL-37 may play a role in protecting against infection and/or the development of COPD. Therefore, treatment with LL-37 may provide a means to increase systemic levels of LL-37, thereby enhancing protection against infection and/or development of COPD.

Studies on sputum showed that LL-37 levels in induced sputum of COPD patients were significantly higher than control subjects, with inverse correlations between sputum LL-37 levels and $\mathrm{FEV}_{1} \%$. LL-37 synthesis polypeptide can induce apoptosis of bronchial epithelial cells and alveolar epithelial cells and promote the release of inflammatory factors. ${ }^{24,25}$ Induced sputum LL-37 levels were significantly higher in I + II COPD and III + IV COPD patients compared with healthy non-smokers and healthy smokers (I + II COPD patients vs III + IV COPD patients vs healthy non-smokers vs healthy smokers) ${ }^{25}$ LL-37 may play an important role in the pathogenesis of COPD. These results suggested that LL-37 may be a valid biomarker for disease activity and progression in COPD. ${ }^{25}$
Mansbach et $\mathrm{a}^{26}$ found similar results as ours in a large multicenter study of infants hospitalized with bronchiolitis, wherein lower levels of serum LL-37 were associated with increased severity of illness. There was also an inverse relationship between LL-37 levels and the most common virus causing bronchiolitis (respiratory syncytial virus). These findings highlight the role of LL-37 in the pathogenesis of bronchiolitis. Hizal et $\mathrm{al}^{27}$ found that serum LL-37 levels were significantly lower in systemic sclerosis patients with interstitial lung disease (ILD). Decreased LL-37 levels may be associated with the development of ILD. Majewski et $a^{28}$ established that the mean level of LL-37 was significantly higher in patients with TB than in those with gram-positive bacteria-induced pneumonia, with gram-negative bacteriainduced pneumonia, and in healthy controls. Their observations clearly documented that cathelicidin LL-37 plays a role in defense mechanisms against infectious agents and is particularly important when the infection is caused by an intracellular pathogen. For this reason, LL-37 may be a possible novel therapeutic target in COPD.

To the best of our knowledge, there is no study of the association of plasma NF- $\mathrm{KB}$ and plasma LL-37 levels in the stable COPD. In the present study, we sought to investigate the clinical value of both plasma NF- $\mathrm{KB}$ and LL-37 and their importance in chronic immune inflammation in COPD. We found that NF-kB levels in the very severe group were significantly higher than in other groups and that $\mathrm{C}$ and $\mathrm{D}$ groups had higher NF- $\mathrm{KB}$ levels than both the control group and A and B groups. The most likely factors in

Table 4 ROC analysis for clinical and laboratory findings of $A+B$ and $C+D$ groups

\begin{tabular}{|l|l|l|l|l|l|l|l|}
\hline AB-CD & AUC & SE & P-value & 95\% CI & Cutoff & Sensitivity (\%) & Specificity (\%) \\
\hline FEV,$(\%)$ & 1.000 & 0.000 & $\leq 0.001$ & $1.000-1.000$ & 53.50 & 100 & 100 \\
\hline FEV $/$ /FVC (\%) & 0.890 & 0.027 & $\leq 0.001$ & $0.836-0.944$ & 57.50 & 91.3 & 63.8 \\
\hline CRP $(\mathrm{mg} / \mathrm{L})$ & 0.419 & 0.049 & 0.099 & $0.323-0.515$ & 0.44 & 42.0 & 46.4 \\
\hline NF-KB $(\mathrm{ng} / \mathrm{mL})$ & 0.389 & 0.048 & 0.025 & $0.294-0.484$ & 3.18 & 65.2 & 30.4 \\
\hline LL-37 (pg/mL) & 0.680 & 0.046 & $\leq 0.001$ & $0.590-0.770$ & 243 & $\mathbf{8 4 . 0}$ & 46.4 \\
\hline
\end{tabular}

Note: Bold type indicates specificity and/or sensitivity values are greater than $80 \%$.

Abbreviations: ROC, Receiver operating characteristic; CRP, C-reactive protein; NF- $\kappa B$, nuclear factor-kappaB; AUC, area under the curve. 
Table 5 ROC analysis for clinical and laboratory findings of controls and A+B groups

\begin{tabular}{|c|c|c|c|c|c|c|c|}
\hline Control-AB & AUC & SE & $P$-value & $95 \% \mathrm{Cl}$ & Cutoff & Sensitivity (\%) & Specificity (\%) \\
\hline $\mathrm{FEV}_{1}(\%)$ & 0.904 & 0.031 & $\leq 0.00 \mathrm{I}$ & $0.844-0.964$ & 91.00 & 90.9 & 84.1 \\
\hline $\mathrm{FEV}_{1} / \mathrm{FVC}(\%)$ & 1.000 & 0.000 & $\leq 0.001$ & $1.000-1.000$ & 73.00 & 100 & 100 \\
\hline CRP (mg/L) & 0.414 & 0.056 & 0.161 & $0.303-0.525$ & 0.23 & 60.6 & 42.0 \\
\hline NF- $\kappa B(n g / m L)$ & 0.330 & 0.053 & 0.006 & $0.226-0.435$ & 3.37 & 30.3 & 42.0 \\
\hline LL-37 (pg/mL) & 0.634 & 0.070 & 0.029 & $0.498-0.770$ & 323 & 69.7 & 50.7 \\
\hline
\end{tabular}

Note: Bold type indicates specificity and/or sensitivity values are greater than $80 \%$.

Abbreviations: ROC, Receiver operating characteristic; CRP, C-reactive protein; NF- $\mathrm{B}$, nuclear factor-kappaB; AUC, area under the curve.

the occurrence of NF- $\kappa \mathrm{B}$ activation in COPD are as follows: response to inflammatory mediators such as interleukin- $1 \beta$ and tumor necrosis factor- $\alpha$ or elicited by the activation of toll-like receptors during bacterial or viral exacerbation. ${ }^{29}$ Higher levels of activated NF- $\mathrm{kB}$ are observed in the bronchial biopsies and inflammatory cells of COPD individuals. ${ }^{10,11}$ In our study, there were inverse correlations between LL-37 and NF- $\kappa B$ in all COPD patients and also between $\mathrm{FEV}_{1}$ and NF- $\mathrm{KB}$ in group IV. NF- $\mathrm{KB}$ has a pivotal role in airway inflammation in COPD. NF- $\kappa B$ pathway plays a critical role in regulating immune response and provides a link between immunity and inflammation. Most of the inflammatory proteins that are upregulated in COPD macrophages are regulated by transcription factor NF- $\kappa \mathrm{B}$, which is activated in alveolar macrophages of patients with COPD, particularly during exacerbations. The source of NF- $\mathrm{\kappa B}$ in the circulation in COPD is probably alveolar macrophages. ${ }^{30}$ Glucocorticoids (GCs), a major treatment for COPD, has anti-inflammatory effects by inhibiting NF- $\mathrm{KB}$-induced gene transcription. Targeting NF- $\mathrm{KB}$ signaling or GC-mediated transrepression of NF- $\mathrm{KB}$ is a potential intervention for steroid-refractory airway disease. ${ }^{9}$ In the near future, plasma $\mathrm{NF}-\kappa \mathrm{B}$ levels may be an important parameter for evaluating the severity of disease in COPD and monitoring response to treatment ( $\mathrm{GC}$ treatment).

Pulmonary function tests (PFTs) are used to assess lung function and determine the degree of damage to lungs, in the diagnosis of COPD ${ }^{31}$ PFTs are also commonly performed to define the grades (stages) of COPD. As expected, severe and very severe groups had significantly lower $\mathrm{FEV}_{1}$ and $\mathrm{FEV}_{1} / \mathrm{FVC}$ levels than other groups in our study. $\mathrm{FEV}_{1}$ and $\mathrm{FEV}_{1} / \mathrm{FVC}$ in $\mathrm{C}$ and $\mathrm{D}$ groups were significantly lower than in controls and A and B groups. PFTs have the best sensitivity and specificity in separating all groups from each other in ROC analysis. Spirometry is a convenient, noninvasive procedure that can be performed in all centers. PFTs with knowledge of normal values and flow volume curves should be interpreted with the patients' clinical history and presentation. The criteria for the application and evaluation of spirometric measurements were defined by the American Thoracic Society/ERS. While many laboratories in our country use international standardization measurements, no national or local standard laboratory measurements have been processed in our national laboratories, yet. Therefore, plasma LL-37 can be used as a noninvasive method in conjunction with PFTs.

The CRP and WBC as classic inflammatory markers in the diagnosis and definition of the severity of COPD may be independent predictors of the severity and clinical findings in our study. In addition to PFTs, which is an essential component for the diagnosis and definition of COPD severity, the frequency of exacerbations, blood inflammatory markers (CRP and leukocyte count), plasma LL-37, and NF- $\kappa B$ levels should also be taken into consideration. ${ }^{32,33}$

There is rapidly growing evidence that mechanisms of surface (or innate) immunity could have a substantial impact

Table 6 ROC analysis for clinical and laboratory findings of controls and all patients

\begin{tabular}{|c|c|c|c|c|c|c|c|}
\hline Control-total patients & AUC & SE & $P$-value & $95 \% \mathrm{Cl}$ & Cutoff & Sensitivity (\%) & Specificity (\%) \\
\hline $\mathrm{FEV}_{1}(\%)$ & 0.952 & 0.016 & $\leq 0.00 \mathrm{I}$ & $0.92 I-0.983$ & 91.00 & 90.9 & 92.0 \\
\hline $\mathrm{FEV}_{1} / \mathrm{FVC}(\%)$ & 1.000 & 0.000 & $\leq 0.00 \mathrm{I}$ & $1.000-1.000$ & 73.00 & 100 & 100 \\
\hline CRP (mg/L) & 0.361 & 0.046 & 0.013 & $0.27 \mid-0.45 I$ & 0.40 & 30.3 & 50.7 \\
\hline $\mathrm{NF}-\kappa \mathrm{B}(\mathrm{ng} / \mathrm{mL})$ & 0.296 & $0.04 I$ & $\leq 0.001$ & $0.215-0.376$ & 2.83 & 60.6 & 26.8 \\
\hline LL-37 (pg/mL) & 0.681 & 0.061 & 0.001 & $0.56 \mathrm{I}-0.800$ & 369 & 60.6 & 78.3 \\
\hline
\end{tabular}

Note: Bold type indicates specificity and/or sensitivity values are greater than $80 \%$.

Abbreviations: ROC, Receiver operating characteristic; CRP, C-reactive protein; NF-אB, nuclear factor-kappaB; AUC, area under the curve. 
on the overall effectiveness of the bronchial defense system during the progression of COPD. ${ }^{34}$ Our study indicated that plasma LL-37 and NF- $\mathrm{BB}$ may play an important role in chronic immune inflammation in COPD. Patients with COPD have several circulating inflammatory markers such as increased CRP, WBC, and NF- $\mathrm{KB}$ levels and decreased LL-37 levels, like in our study. The reasons are not clear, and it remains unknown whether the systemic inflammation is a primary or secondary phenomenon. ${ }^{33}$ Male:female ratio in each group is quite variable in our study. Considering that lung volumes and airway behavior vary between men and women, it is likely that this might affect the study results. As PFTs are noninvasive, it is considered to be a very important tool in diagnosis and definition of COPD. The ideal biomarkers for the severity of COPD should possess high specificity and sensitivity, should be easily accessible, easily measurable, minimally invasive, inexpensive, accurate, and acceptable to patients and physicians. Decreased LL-37 levels may be particularly high risk for patients in stage IV. Our findings also suggest, but do not prove, the role of LL-37 as a target for treatment of the immune system and COPD, which must be widely evaluated. Since multiple factors (eg, other cytokines, other disease processes, genetic factors, etc) affect the levels of LL-37 and NF- $\kappa B$, multiple longitudinal controlled studies would be required to confirm these findings.

\section{Acknowledgment}

This article was presented as a poster in the ERS International Congress 2017 (European Respiratory Journal. 2017;50: PA3613; DOI: 10.1183/1393003.congress-2017.PA3613).

\section{Disclosure}

The authors report no conflicts of interest in this work.

\section{References}

1. Rabe KF, Watz H. Chronic obstructive pulmonary disease. Lancet. 2017;389(10082):1931-1940.

2. Zhou X, Li Q. Exacerbation of chronic obstructive pulmonary disease. Cell Biochem Biophys. 2015;73(2):349-355.

3. Dürr UH, Sudheendra US, Ramamoorthy A. LL-37, the only human member of the cathelicidin family of antimicrobial peptides. Biochim Biophys Acta. 2006;1758(9):1408-1425.

4. Vandamme D, Landuyt B, Luyten W, Schoofs L. A comprehensive summary of LL-37, the factotum human cathelicidin peptide. Cell Immunol. 2012;280(1):22-35.

5. Kahlenberg JM, Kaplan MJ. Little peptide, big effects: the role of LL-37 in inflammation and autoimmune disease. J Immunol. 2013;191(10): 4895-4901.

6. Zhang Y, Jiang Y, Sun C, et al. The human cathelicidin LL-37 enhances airway mucus production in chronic obstructive pulmonary disease. Biochem Biophys Res Commun. 2014;443(1):103-109.
7. Yang YM, Guo YF, Zhang HS, Sun TY. Antimicrobial peptide LL-37 circulating levels in chronic obstructive pulmonary disease patients with high risk of frequent exacerbations. J Thorac Dis. 2015;7(4):740-745.

8. Persson LJ, Aanerud M, Hardie JA, et al. Antimicrobial peptide levels are linked to airway inflammation, bacterial colonisation and exacerbations in chronic obstructive pulmonary disease. Eur Respir J. 2017; 49(3):1601328.

9. Schuliga M. NF-kappaB signaling in chronic inflammatory airway disease. Biomolecules. 2015;5(3):1266-1283.

10. Di Stefano A, Caramori G, Oates T, et al. Increased expression of nuclear factor-kappaB in bronchial biopsies from smokers and patients with COPD. Eur Respir J. 2002;20(3):556-563.

11. Caramori G, Romagnoli M, Casolari P, et al. Nuclear localisation of p65 in sputum macrophages but not in sputum neutrophils during COPD exacerbations. Thorax. 2003;58(4):348-351.

12. Pistolic J, Cosseau C, Li Y, et al. Host defence peptide LL-37 induces IL-6 expression in human bronchial epithelial cells by activation of the NF-kappaB signaling pathway. J Innate Immun. 2009;1(3):254-267.

13. Global Initiative for Chronic Obstructive Lung Disease. "Could it be COPD?" Questionnaire Global initiative for chronic obstructive lung Disease (Gold), global strategy for the diagnosis, management, and prevention of chronic obstructive pulmonary disease, global initiative for chronic obstructive lung Disease (Gold); 2014. Available from: http:// www.goldcopd.org/could-it-be-copd.html. Accessed April 01, 2016.

14. Bals R, Hiemstra PS. Antimicrobial peptides in COPD - basic biology and therapeutic applications. Curr Drug Targets. 2006;7(6):743-750.

15. Gombart AF, Bhan I, Borregaard N, et al. Low plasma level of cathelicidin antimicrobial peptide (hCAP18) predicts increased infectious disease mortality in patients undergoing hemodialysis. Clin Infect Dis. 2009;48(4):418-424.

16. Quraishi SA, De Pascale G, Needleman JS, et al. Effect of cholecalciferol supplementation on vitamin D status and cathelicidin levels in sepsis: a randomized, placebo-controlled trial. Crit Care Med. 2015;43(9): 1928-1937.

17. Ye Y, Carlsson G, Karlsson-Sjöberg JM, et al. The antimicrobial propeptide hCAP-18 plasma levels in neutropenia of various aetiologies: a prospective study. Sci Rep. 2015;5:11685.

18. Pavlov SI, Ivanova II, Gerova DI, Chervenkov TG, Balev SP. Serum level of the human antimicrobial cathelicidin (hCAP18/LL-37) in patients with psoriasis vulgaris. Scripta Scientifica Medica. 2016;48(2): $37-42$.

19. Ashenafi S, Mazurek J, Rehn A, et al. Vitamin D3 status and the association with human cathelicidin expression in patients with different clinical forms of active tuberculosis. Nutrients. 2018;10(6):721.

20. Jiang Y, Xiao W, Zhang Y, Xing Y. Urokinase-type plasminogen activator system and human cationic antimicrobial protein 18 in serum and induced sputum of patients with chronic obstructive pulmonary disease. Respirology. 2010;15(6):939-946.

21. Parameswaran GI, Sethi S, Murphy TF. Effects of bacterial infection on airway antimicrobial peptides and proteins in COPD. Chest. 2011; 140(3):611-617.

22. Golec M, Reichel C, Lemieszek M, et al. Cathelicidin LL-37 in bronchoalveolar lavage and epithelial lining fluids from COPD patients and healthy individuals. J Biol Regul Homeost Agents. 2012;26(4):617-625.

23. Sun C, Zhu M, Yang Z, et al. LL-37 secreted by epithelium promotes fibroblast collagen production: a potential mechanism of small airway remodeling in chronic obstructive pulmonary disease. Lab Invest. 2014; 94(9):991-1002.

24. Golec M, Reichel C, Mackiewicz B, et al. Cathelicidin LL-37, granzymes, TGF-beta1 and cytokines levels in induced sputum from farmers with and without COPD. Ann Agric Environ Med. 2009;16(2):289-297.

25. Jiang YY, Xiao W, Zhu MX, et al. The effect of human antibacterial peptide LL-37 in the pathogenesis of chronic obstructive pulmonary disease. Respir Med. 2012;106(12):1680-1689.

26. Mansbach JM, Hasegawa K, Ajami NJ, et al. Serum LL-37 levels associated with severity of bronchiolitis and viral etiology. Clin Infect Dis. 2017;65(6):967-975. 
27. Hizal M, Bruni C, Romano E, et al. Decrease of LL-37 in systemic sclerosis: a new marker for interstitial lung disease? Clin Rheumatol. 2015;34(4):795-798.

28. Majewski K, Agier J, Kozłowska E, Brzezińska-Błaszczyk E. Serum level of cathelicidin LL-37 in patients with active tuberculosis and other infectious diseases. J Biol Regul Homeost Agents. 2017;31(3):731-736.

29. Edwards MR, Bartlett NW, Clarke D, Birrell M, Belvisi M, Johnston SL. Targeting the NF-kappaB pathway in asthma and chronic obstructive pulmonary disease. Pharmacol Ther. 2009;121(1):1-13.

30. Barnes PJ. Cellular and molecular mechanisms of chronic obstructive pulmonary disease. Clin Chest Med. 2014;35(1):71-86.
31. Ranu H, Wilde M. Madden B: pulmonary function tests. Ulster Med J. 2011;80(2):84-90.

32. Sevenoaks MJ, Stockley RA. Chronic Obstructive Pulmonary Disease, inflammation and co-morbidity - a common inflammatory phenotype? Respir Res. 2006;7(1):70.

33. Milacić N, Milacić B, Milojković M, et al. Correlation of C-reactive protein and COPD severity. Acta Clin Croat. 2016;55(1):41-48.

34. Shaykhiev R, Crystal RG. Innate immunity and chronic obstructive pulmonary disease: a mini-review. Gerontology. 2013;59(6):481-489.

\section{Publish your work in this journal}

The International Journal of COPD is an international, peer-reviewed journal of therapeutics and pharmacology focusing on concise rapid reporting of clinical studies and reviews in COPD. Special focus is given to the pathophysiological processes underlying the disease, intervention programs, patient focused education, and self management protocols.

\section{Dovepress}

This journal is indexed on PubMed Central, MedLine and CAS. The manuscript management system is completely online and includes a very quick and fair peer-review system, which is all easy to use. Visit $\mathrm{http}: / / \mathrm{www}$. dovepress.com/testimonials.php to read real quotes from published authors.

Submit your manuscript here: http://www.dovepress.com/international-journal-of-chronic-obstructive-pulmonary-disease-journal 